\title{
CULTIVATING KNOWLEDGE SHARING AND TRUST IN ONLINE COMMUNITIES FOR EDUCATORS
}

\author{
SHARON ELIZABETH BOOTH \\ North Carolina State University
}

\begin{abstract}
Innovative uses of technology to support teacher learning are emerging through professional learning communities that leverage social networking technologies. The value of an online community for educators lies in the rich and open exchange of ideas, experiences, and resources where educators feel both respected and supported. Yet among the most difficult challenges faced by online communities is fostering and sustaining knowledge sharing and trust. The purpose of this qualitative case study was to examine in-depth successful online learning communities for K-12 educators to better understand ways in which knowledge sharing and trust are cultivated and supported. Cross-case findings indicate knowledge sharing and trust were cultivated and sustained through a clear purpose and common identity, multiple options and opportunities for social learning, the active involvement of an experienced and credible moderator, as well as modeling and enforcement of appropriate online behavior.
\end{abstract}

\section{INTRODUCTION}

Social media is dramatically changing the learning landscape. Daily headlines tout the ways in which students are connecting and collaborating globally with their peers. In parallel form - though less publicized - innovative uses of social networking technologies to support teacher learning and collaboration are also emerging (Baker-Doyle \& Yoon, 2010; Barab, MaKinster, \& Scheckler, 2003;

(C) 2012, Baywood Publishing Co., Inc. doi: http://dx.doi.org/10.2190/EC.47.1.a http://baywood.com 


\section{2 / BOOTH}

Borko, Whitcomb, \& Liston, 2009; Duncan-Howell, 2010; Farooq, Schank, Harris, Fusco, \& Schlager, 2007; Wenger, White, \& Smith, 2009). Social networking technologies offer new opportunities for educators around the world to create and engage in online communities of practice that, like face-to-face communities of practice, can increase communication, collaboration, and support among teachers (Babinski, Jones, \& DeWert, 2001; Chen, Chen, \& Tsai, 2009; Hur \& Brush, 2009; Vavasseur \& MacGregor, 2008). Additionally, these technologies enable teachers to gain equitable access to resources that may not be available due to either location or fiscal constraints (Dede, Ketelhut, Whitehouse, Breit, \& McCloskey, 2009; Loucks-Horsley, Stiles, Mundry, Love, \& Hewson, 2010; Schlager, Farooq, Fusco, Schank, \& Dwyer, 2009). Participation in online communities can reduce feelings of disconnectedness or isolation (DuncanHowell, 2010; Gray, 2004), facilitate informal knowledge sharing across time and space (Duncan-Howell, 2010; Hew \& Hara, 2007; Vavasseur \& MacGregor, 2008; Young \& Tseng, 2008), and support new knowledge creation (Wang, Yang, \& Chou, 2008). The increasing importance of online communities of practice is evident in the U.S. Department of Education's National Education Technology Plan (2010), which calls for the use of social networking technologies "to create communities of practice that provide career-long personal learning opportunities for educators within and across schools, preservice preparation and in-service education institutions, and professional organizations" (p. xviii). The purpose of these communities is to ensure that professional educators have access to the content, resources, data, information, peers, and expertise they need to be highly effective.

While the promise of online communities of practice is great, the realization of success cannot be achieved by simply building an online platform, inviting educators to join, and hoping that they will spontaneously interact in productive ways. An online community can have the right user interface, tools, and ethos, but if community members are not engaged, the community will not flourish (Bishop, 2007). The reasons why some online communities succeed while others fail are complex and varied (Fang \& Chiu, 2010; Farooq et al., 2007; Ke \& Hoadley, 2009; Schlager, Fusco, \& Schank, 2002). Scholars call for further research that will provide reliable evidence about how, when, and why online education communities do or do not support teachers' development of new knowledge and practices (Preece, Nonnecke, \& Andrews, 2004; Schlager et al., 2009).

Among the most difficult challenges faced by online communities is fostering and sustaining knowledge sharing (Barab, Kling, \& Gray, 2004; Chiu, Hsu, \& Wang, 2006; Fang \& Chiu, 2010; Hsu, Ju, Yen, \& Chang, 2007; Lin, Hung, \& Chen, 2009; Prestridge, 2010). Without this ongoing exchange, online communities fail to thrive (Ardichvili, 2008; Chiu et al., 2006; Fang \& Chiu, 2010). A key facilitating factor for knowledge sharing in online communities is trust (e.g., Ardichvili, 2008; Chiu et al., 2006; Hsu et al., 2007; Usoro, Sharratt, 
Tsui, \& Shekhar, 2007; Young \& Tseng, 2008). Functioning as a mechanism to keep the participants in a community integrated and cohesive (Hoy \& TschannenMoran, 1999), trust builds and maintains exchange relationships which can lead to quality knowledge sharing (Bryk \& Schneider, 2002; Levin \& Cross, 2004; Usoro et al., 2007). As growing trust creates fertile ground for knowledge sharing, increased knowledge sharing reciprocally deepens trust (Chiu et al., 2006; Fang \& Chiu, 2010; Usoro et al., 2007). Following a study on motivation and barriers to participation in online knowledge-sharing communities, Ardichvili et al. (2003) recommended that researchers must better understand the mechanisms of trust among community members in order to understand how to overcome the barriers to online knowledge sharing.

\section{PURPOSE OF STUDY}

The purpose of this study was to examine successful online learning communities for K-12 educators in order to better understand the common practices that support and encourage knowledge sharing. Based on the premise that trust and knowledge sharing are mutually reinforcing processes, the study further sought to understand how the practices that support knowledge sharing reciprocally build and strengthen trust. The following research questions framed the study:

1. How is knowledge sharing cultivated in online learning communities for $\mathrm{K}-12$ educators?

2. How is knowledge sharing sustained in online learning communities for $\mathrm{K}-12$ educators?

3. How is trust cultivated in online learning communities for $\mathrm{K}-12$ educators?

4. How is trust sustained in online learning communities for K-12 educators?

Harnessing the power of networking technologies for teacher learning and support holds great promise. Though considerable scholarly research has been conducted on face-to-face learning communities (e.g., Hipp, Huffman, Pankake, \& Olivier, 2008; Louis \& Marks, 1998; Tillema \& Van der Westhuizen, 2006; Vescio, Ross, \& Adams, 2008), research on online communities is only beginning to emerge. It is important that knowledge of online communities be rooted in careful exploration and study of information-rich cases. Simply quantifying participation in online communities (e.g., number of posts, number of members) tells little about the nature of interactions among members (Lin, Lin, \& Huang, 2008; Schlager et al., 2009) or the practices that encourage members' interactions.

\section{Theoretical Framework}

The study was guided by Wenger's (1998) social theory of learning and the theoretical construct of communities of practice (Lave \& Wenger, 1991; Wenger, 
1998). Consistent with Vygotsky's (1978) theory of sociocultural cognitive development, Wenger's theory of learning emphasizes construction of knowledge through interpersonal interactions. Wenger's theory is based on four assumptions:

1. we are social beings;

2. knowledge is a matter of competence with respect to valued enterprises;

3. knowing is a matter of participating in the pursuit of such enterprises; and

4. meaning - our ability to experience the world and our engagement with it as meaningful —is ultimately what learning produces (Wenger, 1998, p. 4).

Within this framework, communities of practice (CoPs) are "groups of people who share a concern, a set of problems, or a passion about a topic, and who deepen their knowledge and expertise in this area by interacting on an ongoing basis" (Wenger, McDermott, \& Snyder, 2002, p. 4). Online communities create a new type of social space in which members can learn together across boundaries of time and place. Examining knowledge sharing and trust in online communities through the lens of social learning theory helps to sharpen the focus on the interwoven and unique complexities of learning within an online social space.

\section{Online Learning Communities}

Online learning communities are not merely websites or database of resources, they are groups of people who come together in an online space to learn, interact, and build relationships, and through this process develop a sense of belonging and mutual commitment (Wenger et al., 2002). Barab et al. (2003) further define a online community as "a persistent, sustained social network of individuals who share and develop an overlapping knowledge base, set of beliefs, values, history, and experiences focused on a common practice and/or mutual enterprise" (p. 238). The success of an online community is typically defined in terms of its effectiveness and health (Bourhis \& Dubé, 2010). Effectiveness is the extent to which a community has met its objectives, provided benefits to members, and, in some cases, provided value to the sponsoring organization.

\section{Knowledge Sharing}

Every practice is in some sense a form of knowledge, and "knowing" is defined only in the context of a specific practice (Wenger, 1998). A practitioner's knowledge is an accumulation of experience - "a kind of 'residue' of their actions, thinking, and conversations - that remains a dynamic part of their ongoing experience" (Wenger et al., 2002, p. 8). Knowledge sharing is defined as a process of communication between two or more participants involving the provision and acquisition of knowledge (Usoro et al., 2007). Wenger notes that communities of practice are well positioned to codify knowledge because they can combine both the tacit and explicit aspects of it. Communities can produce useful documentation, tools, and procedures (explicit knowledge) because they 
understand the needs of practitioners: these products have increased meaning because the explicit knowledge requires the tacit knowledge inherent in the community to be applied (Wenger et al., 2002). Sharing tacit knowledge requires informal learning processes and communication such as storytelling, conversation, mentoring, and encouraging (Wenger et al., 2002).

\section{Trust}

In reference to the application of social learning theory to online communities, Wenger et al. (2009) assert that "learning together depends on the quality of relationships of trust and mutual engagement that members develop with each other" (p. 8). Research has established that trust is among the key enablers for knowledge sharing in online communities (Ardichvili, 2008; Ardichvili, Page, \&Wentling, 2003; Fang \& Chiu, 2010; Feng, Lazar, \& Preece, 2004; Hsu et al., 2007; Ridings, Gefen, \& Arinze, 2002; Sharratt \& Usoro, 2003; Usoro et al., 2007; Young \& Tseng, 2008). Social trust involves a calculation whereby a person decides whether to engage in an action with another individual that incorporates some degree of risk (Bryk \& Schneider, 1996). Hoy and Tschannen-Moran (1999) define trust as a multifaceted concept that encompasses one party's willingness to risk vulnerability based on the confidence that the latter party is benevolent, reliable, competent, honest, and open. Although trust is positively related to knowledge sharing in both face-to-face and online communities, without the facial expressions, verbal cues, and nonverbal cues afforded in face-to-face communities, online communities meet unique challenges in cultivating trust (Ridings et al., 2002; Young \& Tseng, 2008).

\section{METHODS}

\section{Case Selection}

This research was based on a qualitative multiple-case study design (Yin, 2009). Qualitative methods enabled a more detailed understanding of how specific practices of online community moderators and members advanced knowledge sharing and cultivated trust within those communities. Over the course of 1 year, qualitative snowball sampling (Patton, 2002), was used to identify potential cases for the study. As is intended with this form of purposeful sampling, recommendations for potential online communities to study "snowballed" in the beginning and then eventually began to converge. Following the initial identification of 15 communities, a refined set of operational criteria was developed whereby candidate communities were further screened for inclusion as a case (Yin, 2009). The following criteria were used to screen potential cases:

- The primary purpose of the community is to increase knowledge sharing among $\mathrm{K}-12$ educators.

- Participation in the community is voluntary. 
- Participation is not associated with structured courses or workshops promising credit or certification.

- Membership is free.

- The community has exhibited sustained knowledge sharing for at least 1 year. Sustained knowledge sharing is marked by daily knowledge exchange postings.

- The community has clearly defined leadership (Dubé, Bourhis, \& Jacob, 2006) with one or more moderators available to monitor and facilitate community activity.

- Participants are geographically distributed and not limited in affiliation to one school or district.

While three cases were ultimately selected for inclusion in the original study, only two cases and the subsequent findings for those cases are reported here. An initial premise of the study was that each of the communities studied could be considered a "community of practice" (Wenger et al., 2002); however, findings emerging from the analysis of data suggested that the third community was more of a "network" than a "community of practice." Wenger, Trayner, and De Laat (2011) note that, while communities and networks are two aspects of the social learning fabric, participation in a network does not have the "explicit collective dimension" that was of interest in this study. The communities selected for this study have been given pseudonyms, as have the participants in the study.

\section{Case Descriptions}

\section{Case 1: National Education Leaders Network}

The National Education Leaders Network (NELN) is the flagship community for a larger network of teacher communities created by an organization whose mission centers on teacher leadership, research, and policy. The initial goal in forming the NELN community was to create opportunities for teacher leaders to collaborate, share their expertise and experiences, and access resources in ways that would strengthen their voice as practitioners in national discussions of education policy. The community brought together accomplished educatorsState and National Teachers of the Year, Presidential Award Winners, Milken Educators, and teachers who had earned the highest honors from their professional associations - to work on projects, publish their writing and action research, engage in focused online discussions with national experts, and connect with educational decision makers to advocate for best policy and practice. At the time of this study, it was moderated by Paul and included roughly 300 members. Membership required approval by Paul and was typically "by invitation." 


\section{Case 2: English Teachers' Online Community}

The English Teachers' Online Community (ETOC) is for K-12 English teachers. It was created and moderated by Henry, an experienced English teacher and accomplished author. What began in December of 2008 as Henry's quest to support new teachers and engage them in the professional conversation of English teachers, by 2010 had grown into an international learning community of over 20,000 members. Members of ETOC included both experienced and new English teachers; student teachers; and others who supported English teachers including curriculum supervisors, administrators, publishers, editors, and professors. Membership was open to anyone but required registration.

\section{Data Sources}

A strength of case study data collection lies in the ability to draw from multiple sources of evidence (Yin, 2009). Three primary sources of data were used for each case study:

1. an interview with the moderator of the online community;

2. interviews with eight members from each community; and

3. community documentation.

The moderator and member interview protocols were developed based on a review of literature on knowledge sharing and trust in online communities.

\section{Moderator Interviews}

The purpose of interviewing moderators was to better understand practices they had enacted to cultivate and sustain knowledge sharing and the development of trust. The moderator interviews followed four basic lines of inquiry with multiple sub-questions in each category:

- Community structure: How was the community initially structured to create an environment for knowledge sharing?

- Care and feeding: What strategies were used for sustaining knowledge sharing?

- Member roles: What were the characteristics of influential members? In what ways did their roles support and sustain knowledge sharing within the community?

- Trust: In what ways did the practices of the community increase members' confidence that their well-being or reputation would not be harmed by participating in knowledge sharing activities? 


\section{8 / BOOTH}

\section{Member Interviews}

The purpose of interviewing members of the community was to provide a source of data triangulation. For example, were the practices intended to cultivate knowledge sharing, as described by the moderator of the community, the same as those described by the members? Did the practices put in place by community moderators serve their purpose of creating a trusting environment for knowledge sharing? The member interviews mirrored the moderator interviews, asking members to comment on:

- opportunities for knowledge sharing and personal examples of knowledge sharing;

- the role of the moderator;

- influential members of the community; and

- willingness to take risks.

\section{Community Documentation}

Documentation from each community was used as a third source of data to corroborate evidence from the interviews with community moderators and members. Documentation included information on the community website, such as descriptions of the community's purpose, privacy policies, subgroups, and events. Documentation also included newsletters sent out by the community moderator. These sources of data served to provide additional details on activities or processes described by the moderator and members of the community during the interviews. For example, in discussing cultivation of trust within the community, members often mentioned the privacy policies of the community. Accessing the actual privacy policy from the community website allowed for a more detailed analysis of the community's expectations for behavior and member interaction.

\section{Data Analysis}

For each case, all interview data and, when feasible, community documentation was imported into ATLAS.ti, a qualitative data analysis software program. A preliminary coding scheme was established a priori based on a review of the literature. The coding scheme was refined and expanded through interaction with the data. During coding, features of the software were used to sort and group the data in an effort to identify themes. For example, a literature review suggested that guidelines for participation in online communities may help to support the development of trust (Ardichvili et al., 2003). In moderator and member interviews, participants were asked to comment on practices that increased their willingness to risk vulnerability-i.e., their willingness to trust. Several participants mentioned that having group norms explicitly stated helped to cultivate a more trusting environment. In these instances, the 
a priori code "guidelines for participation" was applied. Further analytic induction revealed that the act of "sheriffing" to enforce the participation norms was a critical practice that greatly increased trust within the community. "Sheriffing" was added as a new code to the "trust" code family and applied in subsequent analysis.

Internal validity can be defined as how accurately an account represents participants' realities of the social phenomena under study (Creswell \& Miller, 2000). Validity refers not to the data, but to the inferences drawn from them (Hammersley \& Atkinson, 1983). The following three strategies were used to increase the internal validity of the study:

1. triangulation;

2. member checking; and

3. data saturation.

External validity was increased by thoroughly describing in rich detail the ways in which knowledge sharing and trust were cultivated in each community. Merriam (2002) suggests that the most common way of conceptualizing external validity in qualitative research is as reader generalizability: with the aid of thick, rich description, the readers themselves determine the extent to which the findings of the study can be applied to their context. "Since small, non-random samples are selected purposefully in qualitative research, it is not possible to generalize statistically. A small sample is selected precisely because the researcher wishes to understand the particular in depth, not to find out what is generally true of the many" (Merriam, 2002, p. 28). External validity was further increased by examining practices that support the development of knowledge sharing and trust across communities with different purposes, goals, and membership.

\section{FINDINGS}

Study results are presented below, grouped according to the four research questions.

\section{$R Q$ 1: How is knowledge sharing cultivated in online learning communities for K-12 educators?}

Cultivating implies preparing for use, as in preparing land for planting. For the purpose of this study, cultivating is an act by the creator and/or moderators of the community that prepared the community for knowledge sharing.

\section{National Education Leaders Network}

Interviews with the moderator and members of the NELN community, as well as community documentation, revealed a range of activities and opportunities designed to encourage both tacit and explicit knowledge sharing. These 
opportunities included: structured conversations; collaborative projects with a deliverable; opportunities to blog or write articles; book review "events"; community newsletters; and webinars. In addition to the structured events and activities, an "invitation only" membership policy also aided in cultivating a knowledge sharing environment.

Structured conversations-ELN began as an experiment. Members of the parent organization wondered if teachers would find it useful to participate with their peers in a series of structured online conversations centered on hot topics in education policy. Paul, who eventually became the moderator of NELN, explained that the initial 3-month series of conversations were purposefully limited in duration to keep them from getting stale or requiring too much of a time commitment. Paul further noted that in choosing the topics, they began with "the big meaty teachers topics" - things they knew teachers could "talk until dawn about." Teacher leaders were then hand-picked for the invitation-only event based on the belief that they would contribute to the conversations in meaningful ways. Teachers found the structured conversations to be a powerful and elevating form of knowledge sharing. As the NELN community began to grow and evolve, the practice of providing members with opportunities to participate in structured conversations continued to be an important construct for cultivating a knowledge sharing environment.

Collaborative projects with a deliverable-NELN members also had opportunities to participate in groups that were tasked with co-authoring a white paper or book on a particular policy issue. This was the most formal and scaffolded form of knowledge sharing within the community. NELN's parent organization assembled teams of accomplished educators from across the nation to study important education policy issues in depth and publish their recommendations. Group participants engaged in a series of webinars in which they discussed the issue at hand from a variety of perspectives. Often experts from the field were brought in to lead conversation around a particular topic or provide differing perspectives. Participants received a stipend for their participation and their contribution to the writing.

Blogs and articles - Blogging and writing articles offered another conduit for knowledge sharing among members within the community as well as the broader education community. As a way of recognizing and encouraging member contributions, the blogs of seven community members were regularly featured on the public website. Bloggers received a stipend of $\$ 2,000$ per year with the expectation that they would blog at least once per week. In 2006, NELN launched a partnership with an education magazine, which afforded semi-structured opportunities for NELN members to write articles and blog. Each week, a new article written by a NELN member was featured on the magazine site, further elevating teacher voice and cultivating knowledge sharing. 
Book reviews-Each year, NELN Forum members had an opportunity to participate in the Annual Summer Book Giveaway. Publishers were invited to send review copies of their latest professional books and an annotated list of the books was posted in the community discussion forum. Members were invited to select and review books that intrigued them. Members kept the books and their reviews were added to the community resources database. Often the book reviews also appeared in the NELN Teacher Voices blog series. This opportunity proved to be a fruitful way of cultivating knowledge sharing within the community. Members indicated that book reviews written by fellow community members were more valuable to them than reviews by outside sources.

Newsletter-The NELN Newsletter was posted in the general discussion forum twice a month. Each edition typically included around 30 news blurbs enhanced with photos, cartoons, and pictures. All members interviewed noted that the newsletter was an important source for knowledge sharing. In the 6 months preceding this study, the monthly newsletter generated an average of 47 comments per newsletter by members of the community.

Webinars-Occasionally webinars were hosted within the community. Webinars typically featured national thought-leaders in the field of education policy. In an effort to increase active participation, members were invited to submit questions for the speaker prior to the webinar. Members appreciated this opportunity to have input into the conversation.

Closed membership-All members who were interviewed indicated that they value the closed aspect of the community and the ability to speak openly "behind closed doors." Additionally, the exclusivity of NELN had appeal; participants felt honored to have been selected and eager to join in the conversation with a group of like-minded people. NELN members reported that coming together to discuss education policy issues of great personal and professional importance helped to cultivate a common identity and enabled them to view each other as learning partners.

If you want a group of people from whom you can really draw some insightful comments and thoughtful ideas and who are going to operate with one another in a certain way, then, you know, not every community can be just open to anybody that wants to jump in. So probably the fact that the community has educators in it, totally educators, successful educators who are willing to share, that had appeal. . . . It's the quality of the people that they get, it's the expectations that they set up front, and it's the sigh of collective relief, I think, that people have when they realize that this is going to be professional and productive, it's not going to be, for lack of a better word, yak-yak. (Diane, NELN member) 


\section{English Teachers' Online Community}

Interviews with Henry, the moderator of ETOC, and members of the community revealed a range of opportunities and structures that helped to cultivate an environment for both tacit and explicit knowledge sharing within the community, including: an active discussion forum and sub-group discussion forums; book club events; webstitutes; opportunities for blogging; and social bookmarking.

Discussion forum and group discussions-The main Discussion Forum for the community provided an active hub for knowledge sharing among members. As suggested in the community guidelines, members often used the main discussion forum to pose a question to the group. More than 200 sub-groups within the ETOC provided opportunities for more focused discussions among members. The 20 most popular groups ranged in size from 400 members to almost 2,400 members. While members were free to create new groups based on perceived needs, Henry maintained the right to approve the group. He noted that, in part this is to avoid overlap, but also to make sure that the group had a clear focus. Most groups provided a brief description of the group's purpose and, in some cases, detailed guidelines for posting discussions.

Book club-Henry identified book club conversations as perhaps the most important knowledge sharing opportunity within the community. He cited the highly-evolved criteria for the book club conversations as contributing to their success. For starters, the book had to be "interesting and thought-provoking," a topic that would likely lead to spirited discussion. Also critical to the success of book club conversations was that each one was moderated by the author of the book. Henry indicated that the opportunity to interact with the book's author was a significant draw for members. Guidelines for book club participants were posted at the beginning of each book club discussion and only one conversation ran at a time. Book club participation ranged from 50 participants to well over 100, depending on the topic of the book, the popularity of the author, and the time of the year. Henry explained that coming to understand the "rhythms of the year" had also become a factor in the success of the book club discussions. For example, he noted that summer is a good time to include a more philosophical book because people are "not as hungry for the practical."

Webstitutes - In the summer of 2010, ETOC held its first web-based institute, or "webstitute." The webstitute was a highly successful grassroots effort organized by a small group of leaders from within the community. These leaders, who were among the earliest members of the community, wanted to create a new model for online professional development that was accessible, useful, interactive, forward-thinking, and free. Presentations were designed to provide fellow members with ideas, resources, and strategies for leveraging Web 2.0 tools in the classroom. Organizers hoped to inspire teachers, connect them with 
others who shared their interests, and spark collaborations that could continue throughout the school year.

Blogs - Blogging provides another avenue for knowledge sharing within the community. Over a 10-month period (January-October 2010) an average of 134 blogs were posted per month. Blogging was voluntary and no one in the community was paid to blog.

Social bookmarking - A Diigo group for members of the ETOC community provided yet another effective way to share resources related to teaching literature and writing. Diigo is a social bookmarking website which allows registered users to bookmark and tag web pages. The ETOC Diigo group had roughly 300 members and 1,300 tagged bookmarks. The Diigo group was created and maintained by one of ETOC's core members.

\section{$R Q$ 2: How is knowledge sharing sustained in online learning communities for $\mathrm{K}-12$ educators?}

For the purposes of this study, "sustain" is defined as providing ongoing support or nourishment. In addition to providing a fertile environment for knowledge sharing, online communities also require continuous "care and feeding."

\section{National Education Leaders Network}

As the community's creator and sole moderator, Paul played a central role in sustaining knowledge sharing within the community. Members emphasized the importance of Paul's leadership in keeping the community alive, healthy, and rich in content. One member described Paul as "the grease on the wheel, the person who keeps everything running smoothly in the community." When conversation in the community slowed down, Paul started new discussion strands on a variety of topics and encouraged others to do the same. In the bi-weekly newsletter, Paul took on a cheerleader persona, highlighting published articles written by NELN members, drawing attention to recent blog posts by NELN members, celebrating the thousands of hits a recent article or blog post had received, and touting multiple appearances of NELN members' work on national professional organization sites. He applauded professional happenings in members' lives, described new initiatives of the parent organization, offered lively updates on existing initiatives, and highlighted linkages to outside communities or happenings.

In addition to public efforts to cultivate and sustain knowledge sharing within the community, Paul also worked behind-the-scenes. Referencing Paul's behindthe-scenes work, another member described him as the "wizard behind the curtain." In this role, he actively and purposefully strived to build alliances between members. He identified and recruited bloggers. He recommended people for work in subgroups. Paul strongly believed it was important to check in 
with members frequently and let them know the importance of their voices in the community. Several members of the community commented that Paul's private e-mails to them provided further encouragement to jump into conversation.

Paul is behind any good discussion, whether it's online or whether it's face-to-face, there's some planning, behind-the-scenes planning that is going on, and Paul is that person. He has worked with online communities so long and he seems to have a knack for knowing how to gently nudge people. (Diane, NELN member)

When asked how he felt about Paul reaching out to him individually, NELN member, Jonathan, replied:

As a classroom teacher, I was jazzed, because nobody recognizes what we do. You don't get a whole lot of public recognition in a school. . . Nobody comes to me and asks me educational policy questions, nobody celebrates the thoughts that I have. . . When you're in the policy conversation when you're a classroom teacher, people automatically assume that you can't see the bigger picture and you don't know what you're talking about. So for Paul to recognize and to see value in my ideas was incredibly rewarding and it led to more and more participation.

Influential members of NELN also played a critical role in sustaining knowledge sharing within the community. Evidence of a core group of influentials within the community could be easily identified. NELN core members developed reputations for their different areas of expertise and for the varied roles they played within the community. Influential members were characterized by fellow members as those who have the ability to recognize a problem, analyze it, and offer solutions. NELN interviewees reported that the most influential members of the community were not there to gripe or complain, they were actively publishing and engaging in discussion about elevating teacher voice and improving the quality of the profession at large. Their posts were thoughtful and thoughtprovoking. They further indicated that influential members' posts reflected that they had read about the issue at hand and they supported their thinking with examples, quotes, or evidence from experts in the field. Influential members were often known to challenge and push the thinking of others.

\section{English Teachers' Online Community}

As with NELN, moderation played a critical role in sustaining knowledge sharing within ETOC. One member likened Henry's role to that of "a shepherd" in the ways that he "took care of the community day-by-day, week-by-week." As the creator and moderator of the community, Henry believed that his role was less about directing the conversation in the community and more about setting and maintaining the tone. He used the weekly newsletter as one tool for setting tone, building a sense of community, and creating an atmosphere of trust. 
In the weekly newsletter, he offered words of encouragement to teachers and affirmed the importance of their work. He reminded members about the community's mission and responsibilities and publically praised the work and impact of the community.

In addition to public shepherding of the community, Henry also noted the importance of his behind-the-scenes work: "I think, without blowing my horn too much, it's a lot of the behind-the-scenes stuff that I've done to keep the soil tilled and keep knowledge flowing." Several members agreed, indicating that Henry does a really good job of "being present but not really seen." Hank commented on Henry's behind-the-scenes habits of "tapping people on the shoulder" and saying, "I really like what you're doing here, feel free to step forward a little more." Charles was the recipient of one of these taps when Henry e-mailed him directly to say, "Charles, I'd like to tell you how much I enjoy your thoughtful blog posts. You've become an important member of the community. Keep up the good work."

As part of his behind-the-scenes work, Henry provided guidance and support for community members who wanted to take on leadership roles within the community. Referring to them as "guiding lights," Henry looked to core members of the community to actively participate in discussions, take on leadership responsibilities, and maintain a welcoming supportive atmosphere. Henry additionally noted the importance of letting individuals and groups take an idea, such as the webstitute, and run with it:

If you feel like you've got to be directly involved in everything, you're just going to wear out and it's not going to be sustainable, so there has to be a flexibility in the structure that simultaneously allows for there to be something of a guiding intelligence that oversees the whole organization. Call it a CEO of some sorts, if you want, but someone who is very comfortable letting whole groups of people go off and create what they want to create, so long as it's consistent with the spirit of the community.

In addition to Henry's important role, influential members also played a key role in sustaining knowledge sharing by carrying out the mission of the community. When interviewees were asked how they would describe influential members in the ETOC community, they said these members are consistent, persistent, active, and generous. They are also the ones who think consciously about moving the conversation forward.

\section{RQ 3: How is trust cultivated in online learning communities for $\mathrm{K}-12$ educators?}

\section{National Education Leaders Network}

According to members interviewed, the community environment was one of trust and mutual respect for the competence and credibility of other members. 
Online conversations revealed a willingness among members to take risks by asking difficult questions and putting their own thinking out there for debate and discussion. The willingness to risk vulnerability based on the confidence that other members are benevolent and competent illustrated a foundational aspect of trust as defined by the literature (Hoy \& TschannenMoran, 1999).

Members indicated that the small community provided an ideal place to test out ideas and get feedback before presenting them to a broader audience of educators and policy makers. Members further noted that the closed community of like-minded, accomplished teachers increased their confidence that what was said in the community would stay in the community. Trust in the integrity of fellow members increased their willingness to take calculated risks for the benefit of sharing and learning in a professional collegial environment.

Members of the community said that the invitation process for joining the community provided an indication of the credibility and competence of members who were being recruited. Additionally, in their online profiles, members generously offered both personal and professional information about themselves which, in turn, enabled fellow members to better assess their credibility. Members noted that the credibility and expertise of members subsequently raised the level of expectations for discussion. Tim, a NELN member, stressed the importance of being able to step into an environment where people may not necessarily agree on every topic but they could still have a productive collaborative experience by drawing on the expertise and knowledge of a diverse group of highly accomplished teachers.

\section{English Teachers' Online Community}

Members interviewed felt the ETOC was a safe environment for seeking and providing support. While results of the study did not elevate trust as a major factor in knowledge sharing among ETOC members, a few practices that helped to cultivate a trusting environment could be identified. Henry's credibility as an author, a teacher, and the moderator of an earlier successful community helped to cultivate an environment for knowledge sharing and also aided in establishing trust within the community. Based on their prior knowledge of Henry and interactions with him, community members trusted his competence and credibility, which reciprocally contributed to their willingness to join the community and share their own knowledge.

Henry posted "Principles and Practices" within the ETOC community to help ensure trustworthy behavior among members. Within these guidelines, he states that "ETOC is a community where above all else professionalism is expected, cultivated, and required. All posted content must add positively to our professional neighborhood; therefore, any person whose acts are deemed outside of this basic etiquette may be asked to leave." Members said that 
having those netiquette guidelines clearly posted on the community site and reiterated by Henry and core members helped to cultivate a more trusting environment for knowledge sharing.

\section{RQ 4: How is trust sustained in online learning communities for $\mathrm{K}-12$ educators?}

\section{National Education Leaders Network}

While members were provided with guidelines for participation in the community when they joined, it was the ways in which the informal norms of behavior were put into effect over time that served to build and sustain trust. Paul likened his role in the community to that of a sheriff. After putting years of time and effort into building the community, Paul felt responsible for keeping the community safe. As with a true physical community, people need to feel they are protected and they can be together and carry on with their social discourse without fear of attack. He noted that when people come into the community with "their guns a blazing," he has to be the sheriff. "That," he emphasized, "is a critical part of sustaining trust." Paul also used his core group to help him model good community behavior. When someone in the community needed to be "steered" in a particular direction, he sent an e-mail to a handful of core members and requested their assistance in modeling appropriate behavior. NELN members who were interviewed concurred that it was part of their role to model and enforce appropriate behavior.

\section{English Teachers' Online Community}

Henry also emphasized that setting the right tone is an important factor for sustaining a trusting environment. All interviewees indicated that Henry's newsletters helped to reinforce their shared vision, their sense of community and togetherness, and their ultimate goal of supporting each other. Core ETOC members who felt a professional responsibility to mentor or help out new teachers also helped to sustain trust within the community. One such member noted that: "The purpose of the site is to help one another, so I try to keep that in mind. You want to help people, you want to elevate them, you want to say things that make teaching better for them and for their students, and we all have to buy into that." Like Paul, Henry also believed that part of his role involved "sheriffing the streets of Dodge" to make sure that members are being good community citizens. At times when conversations became heated or too personal, Henry would jump in to say: "You know, we're here to be kind to each other and to help each other, not to yell at each other." Members indicated that on the few occasions when Henry stepped in, everyone listened and the inappropriate behavior stopped immediately. 


\section{DISCUSSION}

While the domain, the size, and the opportunities for knowledge sharing in NELN and ETOC varied, they were each designed to support and extend teacher learning. This discussion examines the ways in which knowledge sharing was both cultivated and sustained across communities and ties current findings to existing literature. Discussion of knowledge sharing factors is followed by an examination of the ways in which trust was cultivated and sustained across communities.

\section{Cultivating and Sustaining Knowledge Sharing}

\section{Purpose, Collective Identity, and Recruitment}

This study lends further support to prior findings by Carr and Chambers (2006) and Jones and Preece (2006) that a clear purpose and a collective identity among community participants are important for cultivating a knowledge sharing environment. Both of the communities in this study began with a clear focus that could be articulated in one sentence. The stated purpose of the community provided a grounding point for activity within the community. NELN is a relatively small, tight, closed online community of committed teacher leaders from across the country. Members are clear about the community's purpose and strongly committed to elevating teacher voice in national discussions of education policy and practice. ETOC members are bonded by a passion for teaching English. Members buy into Henry's vision of creating a nurturing and supportive community where new teachers feel safe asking for help and experienced teachers give freely of their expertise and experiences. Consistent with Jones and Preece's (2006) suggestion that selective recruitment of members may support the development of a shared vision, recruitment of national teacher leaders to NELN and English teachers to ETOC rooted the community's vision and purpose in the shared domain and practice of its members. As NELN evolved and members became immersed in writing blogs, magazine articles, and white papers around educational policy, the purpose of the community - to raise teacher voice in national conversations of education policy-became clearer to members, and their common identity more firmly established. This, in turn, created more fertile ground for knowledge sharing among members. Paul took active steps to nurture that shared vision and collective identity through his behind-the-scenes work to push and encourage teachers to write and make their voices heard. In ETOC, Henry continually reiterated the purpose of the community and the shared identity of its members through weekly newsletters: "We are English teachers and we are here to nurture and support each other." Evidence of the collective identity of members as English teachers and the shared vision to nurture and support each other could easily be identified within the community. 


\section{Multiple Options and Opportunities for Knowledge Sharing}

As noted at the outset of this study, existing research on online communities provides only small glimpses of insight into the specific practices that spark and sustain knowledge sharing among members of the community. Research by Duncan-Howell (2010) suggests that teachers who engage in online communities are looking for participatory learning that directly relates to practice, opportunities to share professional knowledge and engage in professional discussions, as well as the ability to enjoy collegial support and experience a sense of camaraderie and belonging. Gray's (2004) study of coordinators of Alberta Community Adult Learning Councils participating in an online community illustrates how story-telling and the development of a shared repertoire of stories and cases functioned as a dynamic knowledge source for members of the community. These shared stories and cases helped to sustain knowledge sharing over time. Vavasseur and MacGregor's (2008) research on teachers' and principals' use of online communities to extend content-focused professional development provides another example. This study contributes to an emerging body of literature that examines specific opportunities for sustaining knowledge sharing in online communities.

Perhaps the most important contribution this study makes to the literature is to identify the generative potential of "structured conversations" and other types of structured interactions for sustaining and extending knowledge sharing within online communities. Online "structured conversations" are defined as those that begin with an overarching question or issue of focus, proceed according to a pre-determined set of guidelines, are moderated, and take place during a bounded timeframe. The notion of structured conversations came to light in the interview with Paul. Intrigued with the idea of structured conversations as a construct for knowledge sharing, subsequent analysis of data from the ETOC revealed that the immensely popular book club conversations hosted within the ETOC community provide another form of structured conversations. From a theoretical perspective, structured conversations in online communities enable sustained mutual engagement around a practice, allowing members to explore good practice, articulate perspectives, accumulate knowledge, and create a shared context for ongoing exchanges (Wenger et al., 2009). From a practical perspective, the combination of a limited time frame and a highly focused discussion around a hot topic with supporting resources and guidelines for participation was appealing and valuable to busy educators. This finding lends further support to the findings of Dubé et al. (2006) who examined the impact of structuring characteristics on online communities and found that the activity of successful communities centered on structured topics of conversation that were highly or moderately relevant to the daily concerns of members.

Another important facet of structured conversations in online communities of practice is the record of the conversation that remains as an artifact for later reference. Wenger et al. (2009) posit that meaningful learning in social contexts 
requires not only direct engagement in activities, conversations, and other forms of participation, but also the production of physical and conceptual artifacts. They refer to the words, tools, concepts, methods, stories, documents, links to resources, and the like as forms of "reification."

\footnotetext{
Meaningful learning in a community requires both participation and reification to be present and in interplay. Sharing artifacts without engaging in discussions and activities around them impairs the ability to negotiate the meaning of what is being shared. Interacting without producing artifacts makes learning depend on individual interpretation and memory and can limit its depth, extent, and impact. Both participation and reification are necessary. (Wenger et al., 2007, pp. 51-58)
}

The process of participation and reification is fundamental to the learning theory underlying the concept of communities of practice (Wenger et al., 2009). The technology undergirding each community in this study supported and contributed to both participation and reification. In each community, these structured conversations facilitated a flexible learning agenda that was rooted in the stated purpose of the community but evolved based on the learning needs and interests of the community. The conversations not only encouraged participation, they resulted in reification of the ideas and concepts that were discussed. While participation and reification can occur without purposeful structured conversation, evidence from this study suggests that structured conversations are a viable practice for cultivating and sustaining knowledge sharing within online communities.

\section{The Role of the Moderator}

Wenger (2009) characterizes the leaders of communities of practice as "social artists" whose energy, skills, and craft are a driving force in the success of the community.

Social artists have a good understanding, sometimes completely implicit and intuitive, of the social discipline that makes social learning spaces productive. They have a knack for making people feel comfortable and engaged. They generate social energy among participants. They have a nose for the cultural and personal clues to social dynamics. They produce a climate of high trust and aspirations. (Wenger, 2009, p. 10)

Consistent with prior research (e.g., Bourhis, Dubé, \& Jacob, 2005; GairínSallán, Rodríguez-Gómez, \& Armengol-Asparó, 2010; Gray, 2004; Prestridge, 2010; Wenger et al., 2002), findings from this study underscore the importance of leadership for cultivating and sustaining a knowledge sharing environment and facilitating the development of trust in online communities. Prior research has established the essential role that the moderator plays in online communities. In her study of the experiences of coordinators of Alberta Community Adult Learning Councils who participated in an online CoP designed to support 
workplace learning, Gray found that the presence of a moderator who is attuned to the cultural, social, and organizational issues of a particular practice is essential for sustaining the online community over an extended period and enabling it to evolve beyond superficial interactions. This study yields a similar finding to that of Gray (2004). In both of the communities that were the focus of this study, the moderator exhibited knowledge of cultural, social, and organizational issues related to the practice of teaching and, more specifically, the particular domain of the community. This knowledge enabled the moderators to effectively guide members of the community to richer forms of knowledge sharing. Bourhis et al. (2005) also emphasized the important role of the moderator and discussed basic characteristics of successful moderators. For example, effective moderators had the ability to build alliances, foster trust, and find innovative ways to encourage participation. This study lends support to those findings. Through their research, Gairín-Sallán et al. (2010) delineated the specific functions of the moderator, including the organizational function, the intellectual function, the social function, and the technological function. Cross-case findings from this study affirm Gairín-Sallán et al.'s delineation of the four functions of the moderator and further suggest that the technological function is the least critical.

Findings from this study extend prior research that identifies the important role of the moderator by providing rich examples of both the visible work of the moderator as well as behind-the-scenes work of the moderator. The findings illustrate how the moderators of each community used social artistry to cultivate and sustain knowledge sharing. For example, Paul used behind-the-scenes e-mails to pull multiple voices into conversations, creating a tapestry of rich discussion and contribution by members. His acknowledgments of community members' accomplishments in monthly newsletters also sparked passion and pride among community members for their individual and collective work within the domain of their practice. Similarly, Henry's weekly newsletters provided a canvas on which he used his own experience and identity as an English teacher to inspire members, invite meaningful participation in the community, and create a web of trust. Through their daily involvement in the community, both moderators skillfully elevated the voices of practice, engendered a strong sense of community ownership among members, and facilitated connections and relationships.

\section{Member Roles}

Within each community, members took on unofficial roles. Interview data suggested that the roles played by various members were instrumental in sustaining knowledge sharing. Through interviews with members, several recognized informal roles emerged, including pot-stirrer, playful antagonist, thought leader, peace keeper, and mentor. The unofficial roles that members played in both communities were based on both the personalities and the knowledgeability of the members who assumed them. Knowledgeability, as described by Wenger (2009), 
is a form of social identity that is anchored in practice. Each member brings to the community their stories, experiences, and expertise. Through the ongoing exchange of this knowledge, they develop social identities within the community. Over time, these identities may evolve into informal community roles. Along with the moderator of the community, the people who assume these roles propagate a knowledge sharing environment and the development of trust. Prior research by Ardichvili et al. (2003) indicated that one of the difficulties in enabling online communities is supporting and enriching individual members' uniqueness within the context of the community and linking that uniqueness with the community's purpose. However, emerging research (e.g., Daly, 2010) that uses social network analysis to more systematically understand the social structure and potential of informal social learning in communities offers new insights into how knowledge sharing can be cultivated and sustained through the members of communities and their social identities. Coburn, Choi, and Mata (2010) suggest that members' knowledge of each other's existing expertise can be a key component in network formation, resulting in networks that not only have increased expertise but also the potential to strategically access this expertise to enhance individual and community functioning. Baker-Doyle and Yoon (2010) posit that "expertise transparency" is a key driver for strengthening social networks in teacher professional development. While technology facilitates the development of expertise transparency (Baker-Doyle \& Yoon, 2010), findings from their study of teachers' social networks suggest that the size of the community also influences the potential for expertise transparency. Applied to the findings of this study, Coburn et al.'s and Baker-Doyle and Yoon's research suggest that the small membership of the NELN community, the detailed profiles provided by members, and opportunities for collaborative authorship on white papers and books may have helped to increase expertise transparency among members and thus increase and sustain knowledge sharing.

\section{Cultivating and Sustaining Trust}

For the purposes of discussion, the factors that served to both cultivate and sustain trust within NELN and ETOC are combined and discussed below.

Tschannen-Moran and Hoy (2000) posit that building trust requires attention to five facets of trust. In order to be regarded as trustworthy, a person must demonstrate benevolence, reliability, competence, honesty, and openness. Findings from this study reveal evidence of all facets of trust being demonstrated by the moderator and members of the community; however, competence was frequently mentioned as the most important dimension of trust among members of the online communities. Community members were more likely to trust other members of the community if they perceived that the person was competent within a particular knowledge domain. Further, findings from this study indicate that members' 
trust in the competence of other members and in the credibility of the moderator increased their willingness to engage in knowledge-sharing activities.

Consistent with findings from Hew and Hara's (2007) study of the motivators and barriers of teacher online knowledge sharing, as well as implications from Fang and Chiu's (2010) study of knowledge-sharing continuance intentions in online communities of practice, findings from this study underscore that the moderator plays an important role in cultivating a trusting environment by enforcing trustworthy behavior. This study also builds on prior research by illuminating the role of "sheriff" that community moderators often play. As sheriff of a community, community moderators assume responsibility for enforcing trustworthy behavior. They earn their right to wear a sheriff's badge through their competence, credibility, and reliability.

Moolenaar and Sleegers' (2010) latest research using social network theory to examine social networks, trust, and innovation explicates the relationships between social network characteristics and trust. Their findings suggest that dense networks of teachers engaged in a common exchange of work-related information and discourse contributes to the development of trust. In reflecting on the findings from this study, it is not surprising that trust was particularly salient in the NELN community where teachers had the opportunity to work collaboratively in small groups focused on particular problems of practice. Trust also tended to deepen when members of the ETOC community worked together to host a summer webstitute or engaged collaboratively in thinking about problems of practice raised in book club conversations. Indications from this study that structured interactions around problems of practice provide an important vehicle for knowledge-sharing, lend support to Moolenaar and Sleegers' recommendation that educational practitioners invest time and energy in building strong networks of teachers that focus on work-related discussions. It is through these interactions that teachers have the opportunity to build trust that leads to increased knowledge sharing. Further, these findings affirm results from previous studies of online communities (e.g., Fang \& Chiu, 2010; Lin, 2006; Ridings et al., 2002; Usoro et al., 2007) that establish trust and knowledge sharing as mutually reinforcing processes.

\section{Implications for Practice}

The cases of this study provide a better understanding of online communities as social learning spaces. While the findings do not result in a recipe for creating and sustaining successful communities that could be implemented in isolation of the myriad of contextual factors from which they arose, they do have implications for practitioners. The following suggestions, based on the prior discussion of salient findings, are offered as points of consideration for practitioners who are creating and/or stewarding online communities of practice. 


\section{Cultivating and Sustaining Knowledge Sharing}

This study underscores the importance of leadership in online communities. Without the social artistry and guidance of a single leader or a team of leaders, online communities will unlikely reach their full knowledge sharing potential. In addition to formally recognized moderator roles within the community, the findings of this study also suggest that influential members of the community may play an integral role in the interactions and social learning of a community. Their energy, involvement, and unique contributions can create and sustain a rich environment for knowledge sharing interactions. Supporting the development of informal member roles within the community by increasing expertise transparency may help to increase knowledge sharing and the deepening of trust among members. Patterns in the findings from this study suggest that structured interactions among members can serve to both anchor the vision and collective goals of the community, while simultaneously creating new knowledge frontiers for exploration by members. Based on the major findings of the study related to cultivating and sustaining knowledge sharing, Table 1 delineates specific implications for practice.

\section{Cultivating and Sustaining Trust}

Trust is a key facilitating factor for knowledge sharing in online communities. While many of the practices that cultivate and sustain knowledge sharing in online communities reciprocally help to establish and deepen trust among members of a community, there are additional practices that exhibit promise for increasing and sustaining trust. Based on the findings related to trust from this study, implications for practice are offered in Table 2.

\section{RECOMMENDATIONS FOR FUTURE RESEARCH}

The potential of structured conversations and/or other structured interactions in online communities revealed through this study suggests possibilities for future research. The findings of this study are consistent with the view that the social interactions and work-related discourse between educators that lie at the heart of successful educational innovation are a valuable resource that has only just begun to be tapped (Moolenaar \& Sleegers, 2010). The use of design-based research (DBR) methodology to study the potential of structured conversations in different online community contexts and for different purposes would provide tangible examples of knowledge sharing among educators, better ties between theory and practice, and would acknowledge learning in context (Collins, Joseph, \& Bielaczyc, 2006; Dede et al., 2009).

While results of this study shed some light on informal member roles within online communities, additional research is needed to better understand the role 
Table 1. Cultivating and Sustaining Knowledge Sharing: Implications for Practice

Major findings Implications for practice

Collective identity, • Determine the target audience for the community; engage clear purpose, recruitment in targeted recruitment of members.

- Identify the common interests and concerns related to practice that members share.

- Determine the purpose of the community as it relates to the common interests and problems of practice that members share.

- State the purpose of the online community on the community website.

- Frequently reiterate the purpose of the community through ongoing communications such as weekly or monthly newsletters.

- Identify avenues for participation, indicating ways in which they directly relate to the purpose of the community.

Multiple options and opportunities for knowledge sharing
- Provide a range of opportunities for members to engage in the community. Options should include informal knowledge-sharing opportunities such as online discussion forums, as well as more organized opportunities such as webstitutes or other collaborative projects.

- Provide members with opportunities to participate in structured conversations that center on hot topics, are limited in duration, and result in tangible resources, links, documents, or the like.

- To increase the impact of members' experiences in the community, directly link knowledge-sharing opportunities to problems of practice.

- Select a well-connected community leader who has competence and credibility within the field.

- Select a community leader who is attuned to key issues, passions, and concerns of the group.

- Select a community leader with excellent online communication skills and experience moderating online communities.

- Recognize the time commitment needed to lead the community; allow and compensate for that time accordingly.

Member roles
- Acknowledge and support informal member roles that emerge.

- Increase expertise transparency through detailed user profiles to facilitate development of unique member identities.

- Provide opportunities for collaboration in which members are invited to share their specific expertise. 
Table 2. Cultivating and Sustaining Trust: Implications for Practice

\begin{tabular}{ll}
\hline Major findings & \multicolumn{1}{c}{ Implications for practice } \\
\hline $\begin{array}{l}\text { Guidelines for } \\
\text { participation }\end{array}$ & $\begin{array}{l}\text { • Establish guidelines for participation in the community } \\
\text { upfront and post these guidelines on the community } \\
\text { website. }\end{array}$ \\
$\begin{array}{l}\text { Trustworthy } \\
\text { behavior }\end{array}$ & $\begin{array}{l}\text { - Enforce trustworthy behavior. } \\
\text { - Call on core members of the community to model desired } \\
\text { community behavior and interaction. }\end{array}$ \\
$\begin{array}{l}\text { Competence } \\
\text { and credibility } \\
\text { of members }\end{array}$ & $\begin{array}{l}\text { - Provide mechanisms and opportunities for members to } \\
\text { share their expertise and experiences. }\end{array}$ \\
\hline
\end{tabular}

of influential members in cultivating and sustaining knowledge sharing and trust. Use of Social Network Analysis (SNA) as a methodological tool may be helpful in analyzing the interactions and connections of influential members. Recent research by Baker-Doyle and Yoon $(2010,2011)$ used SNA to examine the ways in which informal teacher networks maximized teachers' access to resources, information, and support for effective teaching. They suggest that SNA may help to reveal the distribution of content knowledge in a network of teachers and enable researchers to better understand how to foster and sustain knowledge sharing. Future research should identify influential members in online communities and use SNA to better understand how they function within the context of a particular community and perhaps across communities.

Online learning communities have great potential to provide a form of ongoing professional development and support for teachers. Situated in the context of teachers' everyday work, they facilitate informal knowledge sharing, the transfer of expertise and experiences, and the exchange of ideas in ways that contribute to teachers' continual professional learning. They enable teachers to gain equitable access to human and information resources that may not be available locally and that can reduce feelings of disconnectedness or isolation. In addition to enabling members to share existing knowledge, online communities provide an environment for new knowledge creation. As our world becomes increasingly digital and connected, it is essential that we find ways of leveraging the power of social networks to support, encourage, and sustain professional learning. This study contributes to our base of knowledge for understanding successful online communities by identifying specific practices that cultivate and sustain knowledge sharing and trust in online communities. 


\section{REFERENCES}

Ardichvili, A. (2008). Learning and knowledge sharing in online communities of practice: Motivators, barriers, and enablers. Advances in Developing Human Resources, 10(4), 541-554. doi: 10.1177/1523422308319536

Ardichvili, A., Page, V., \& Wentling, T. (2003). Motivation and barriers to participation in online knowledge-sharing communities of practice. Journal of Knowledge Management, 7(1), 64-77. doi: 10.1108/13673270310463626

Babinski, L. M., Jones, B. D., \& DeWert, M. H. (2001). The roles of facilitators and peers in an online support community for first-year teachers. Journal of Educational \& Psychological Consultation, 12(2), 151-169. doi: 10.1207/S15327 68XJEPC1202_05

Baker-Doyle, K., \& Yoon, S. A. (2010). Making expertise transparent: Using technology to strengthen social networks in teacher professional development. In A. J. Daly (Ed.), Social network theory and educational change (pp. 115-126). Cambridge, MA: Harvard University Press.

Baker-Doyle, K. J., \& Yoon, S. A. (2011). In search of practitioner-based social capital: A social network analysis tool for understanding and facilitating teacher collaboration in a US-based STEM professional development program. Professional Development in Education, 37(1), 75-93. doi: 10.1080/19415257. 2010.494450

Barab, S. A., Kling, R., \& Gray, J. H. (2004). Introduction: Designing for online communities in the service of learning. In S. A. Barab, R. Kling, \& J. H. Gray (Eds.), Designing for online communities in the service of learning (pp. 3-15). New York: Cambridge University Press.

Barab, S. A., MaKinster, J. G., \& Scheckler, R. (2003). Designing system dualities: Characterizing a web-supported professional development community. Information Society, 19(3), 237-256. doi: 10.1080/01972240309466

Bishop, J. (2007). Increasing participation in online communities: A framework for human-computer interaction. Computers in Human Behavior, 23(4), 1881-1893. doi: 10.1016/j.chb.2005.11.004

Booth, S. E. (2011). Cultivating knowledge sharing and trust in online communities for educators: A multiple case study. Unpublished dissertation North Carolina State University, Raleigh, NC.

Borko, H., Whitcomb, J., \& Liston, D. (2009). Wicked problems and other thoughts on issues of technology and teacher learning. Journal of Teacher Education, 60(1), 3-7. doi: $10.1177 / 0022487108328488$

Bourhis, A., \& Dubé, L. (2010). "Structuring spontaneity": Investigating the impact of management practices on the success of virtual communities of practice. Journal of Information Science, 36(2), 175-193. doi: 10.1177/0165551509357861

Bourhis, A., Dubé, L., \& Jacob, R. (2005). The success of online communities of practice: The leadership factor. The Electronic Journal of Knowledge Management, 3(1), 23-34.

Bryk, A., \& Schneider, B. (1996). Social trust: A moral resource for school improvement. Chicago: University of Chicago, Center for School Improvement.

Bryk, A., \& Schneider, B. (2002). Trust in schools: A core resource for improvement. New York: Russell Sage Foundation. 
Carr, N., \& Chambers, D. P. (2006). Teacher professional learning in an online community: The experiences of the national quality schooling framework pilot project. Technology, Pedagogy and Education, 15(2), 143-157. doi: 10.1080/14759390600 769094

Chen, Y., Chen, N.-S., \& Tsai, C.-C. (2009). The use of online synchronous discussion for web-based professional development for teachers. Computers \& Education, 53(4), 1155-1166. doi: 10.1016/j.compedu.2009.05.026

Chiu, C.-M., Hsu, M.-H., \& Wang, E. T. G. (2006). Understanding knowledge sharing in online communities: An integration of social capital and social cognitive theories. Decision Support Systems, 42(3), 1872-1888.

Coburn, C. E., Choi, L., \& Mata, W. (2010). "I would go to her because her mind is math": Network formation in the context of a district-based mathematics reform. In A. J. Daly (Ed.), Social network theory and educational change (pp. 33-50). Cambridge, MA: Harvard University Press

Collins, A., Joseph, D., \& Bielaczyc, K. (2006). Design research: Theoretical and methodological issues. The Journal of the Learning Sciences, 13(1), 15-42. doi: 10.1207/ s15327809j1s301_2

Creswell, J., \& Miller, D. L. (2000). Determining validity in qualitative inquiry. Theory into Practice, 37(3), 124-130. doi: 10.1207/s1543042tip3903 2

Daly, A. J. (Ed.). (2010). Social network theory and educational change. Cambridge, MA: Harvard Education Press.

Dede, C., Ketelhut, J., Whitehouse, P., Breit, L., \& McCloskey, E. M. (2009). A research agenda for online teacher professional development. Journal of Teacher Education, 60(1), 8-19. doi: 10.1177/0022487108327554

Dubé, L., Bourhis, A., \& Jacob, R. (2006). Towards a typology of online communities of practice. Interdisciplinary Journal of Information, Knowledge, and Management, $1(2), 145-166$.

Duncan-Howell, J. (2010). Teachers making connections: Online communities as a source of professional learning. British Journal of Educational Technology, 41(2), 324-340. doi: 10.1111/j.1467-8535.2009.00953.x

Fang, Y. H., \& Chiu, C. M. (2010). In justice we trust: Exploring knowledge-sharing continuance intentions in online communities of practice. Computers in Human Behavior, 26, 235-246. doi: 10.1016/j.chb.2009.09.005

Farooq, U., Schank, P., Harris, A., Fusco, J., \& Schlager, M. (2007). Sustaining a community computing infrastructure for online teacher professional development: A case study of designing Tapped In. Computer Supported Cooperative Work (CSCW), 16(4), 397-429. doi: 10.1007/s10606-007-9049-0

Feng, J., Lazar, J., \& Preece, J. (2004). Empathy and online interpersonal trust: A fragile relationship. Behaviour \& Information Technology, 23(2), 97-106. doi: 10.1080/ 01449290310001659240

Gairín-Sallán, J., Rodríguez-Gómez, D., \& Armengol-Asparó, C. (2010). Who exactly is the moderator? A consideration of online knowledge management network moderation in educational organisations. Computers \& Education, 55(1), 304-312. doi: 1016/ j.compedu.2010.01.016

Gray, B. (2004). Informal learning in an online community of practice. Journal of Distance Education, 19(1), 20-35. 
Hew, K., \& Hara, N. (2007). Empirical study of motivators and barriers of teacher online knowledge sharing. Educational Technology Research \& Development, 55(6), 573-595. doi: 10.1007/s11423-007-9049-2

Hipp, K., Huffman, J., Pankake, A., \& Olivier, D. (2008). Sustaining professional learning communities: Case studies. Journal of Educational Change, 9(2), 173-195. doi: 10.1007/ s10833-007-9060-8

Hoy, W. K., \& Tschannen-Moran, M. (1999). Five faces of trust: An empirical confirmation in urban elementary schools. Journal of School Leadership, 9(3), 184-208.

Hsu, M.-H., Ju, T. L., Yen, C.-H., \& Chang, C.-M. (2007). Knowledge sharing behavior in online communities: The relationship between trust, self-efficacy, and outcome expectations. International Journal of Human-Computer Studies, 65(2), 153-169. doi: 10.1016/j.ijhcs.2006.09.003

Hur, J. W., \& Brush, T. A. (2009). Teacher participation in online communities: Why do teachers want to participate in self-generated online communities of K-12 teachers? Journal of Research on Technology in Education, 41(3), 279-303.

Jones, A., \& Preece, J. (2006). Online communities for teachers and lifelong learners: A framework for comparing similarities and identifying differences in communities of practice and communities of interest. International Journal of Learning Technology, 2(2), 112-137. doi: 10.1504/IJLT.2006.010615

Ke, F., \& Hoadley, C. (2009). Evaluating online learning communities. Educational Technology Research and Development, 57(4), 487-510. doi: 10.1007/s11423-0099120-2

Lave, J., \& Wenger, E. (1991). Situated learning: Legitimate peripheral participation. Cambridge: Cambridge University Press.

Levin, D. Z., \& Cross, R. (2004). The strength of weak ties you can trust: The mediating role of trust in effective knowledge transfer. Management Science, 50(11), 1477-1490. doi: $10.1287 / \mathrm{mnsc} .1030 .0136$

Lin, F. R., Lin, S. C., \& Huang, T. P. (2008). Knowledge sharing and creation in a teachers' professional online community. Computers \& Education, 50(3), 742-756. doi: 10.1016/j.compedu.2006.07.009

Lin, H.-F. (2006). Understanding behavioral intention to participate in online communities. Cyber Psychology \& Behavior, 9(5), 540-547. doi: 10.1089/cpb.2006.9.540

Lin, M. J., Hung, S. W., \& Chen, C. J. (2009). Fostering the determinants of knowledge sharing in professional online communities. Computers in Human Behavior, 25(4), 929-939. doi: 10.1016/j.chb.2009.03.008

Loucks-Horsley, S., Stiles, K. E., Mundry, S., Love, N., \& Hewson, P. W. (2010). Designing professional development for teachers of science and mathematics (3rd ed.). Thousand Oaks, CA: Corwin Press.

Louis, K. S., \& Marks, H. M. (1998). Does professional community affect the classroom? Teachers' work and student experiences in restructuring schools. American Journal of Education, 106(4), 532-575. doi: 10.1086/444197

Moolenaar, N. M., \& Sleegers, P. J. (2010). Social networks, trust, and innovation. In A. J. Daly (Ed.), Social network theory and educational change (pp. 97-114). Cambridge, MA: Harvard University Press.

Patton, M. Q. (2002). Qualitative research and evaluation methods (3rd ed.). Thousand Oaks, CA: Corwin Press. 
Preece, J., Nonnecke, B., \& Andrews, D. (2004). The top five reasons for lurking: Improving community experiences for everyone. Computers in Human Behavior, 20(2), 201-223. doi: 10.1016/j.chb.2003.10.015

Prestridge, S. (2010). ICT professional development for teachers in online forums: Analyzing the role of discussion. Teaching and Teacher Education, 26(2), 252-258. doi: 10.1016/j.tate.2009.04.004

Ridings, C. M., Gefen, D., \& Arinze, B. (2002). Some antecedents and effects of trust in online communities. Journal of Strategic Information Systems, 11(3-4), 271-295. doi: 10.1016/S0963-8687(02)00021-5

Schlager, M. S., Farooq, U., Fusco, J., Schank, P., \& Dwyer, N. (2009). Analyzing online teacher networks: Cyber networks require cyber research tools. Journal of Teacher Education, 60(1), 86-100. doi: 10.1177/0022487108328487

Schlager, M. S., Fusco, J., \& Schank, P. (2002). Evolution of an on-line education community of practice. In K. A. R. a. W. Shumar (Ed.), Building virtual communities: Learning and change in cyberspace. New York: Cambridge University Press.

Sharratt, M., \& Usoro, A. (2003). Understanding knowledge-sharing in online communities of practice. Electronic Journal of Knowledge Management, 1(2), 187-196.

Tillema, H., \& Van der Westhuizen, G. (2006). Knowledge construction in collaborative enquiry among teachers. Teachers and Teaching: Theory and Practice, 12(1), 51-67.

Tschannen-Moran, M., \& Hoy, W. K. (2000). A multidisciplinary analysis of the nature, meaning, and measurement of trust. Review of Educational Research, 70(4), 547-593. doi: $10.3102 / 00346543070004547$

U.S. Department of Education. (2010). Transforming American education: Learning powered by Technology. Alexandria, VA: ED Pubs.

Usoro, A., Sharratt, M. W., Tsui, E., \& Shekhar, S. (2007). Trust as an antecedent to knowledge sharing in virtual communities of practice. Knowledge Management Research \& Practice, 5(3), 199-212.

Vavasseur, C., \& MacGregor, S. (2008). Extending content-focused professional development through online communities of practice. Journal of Research on Technology in Education, 40(4), 517-536.

Vescio, V., Ross, D., \& Adams, A. (2008). A review of research on the impact of professional learning communities on teaching practice and student learning. Teaching and Teacher Education: An International Journal of Research and Studies, 24(1), 80-91. doi: 10.1016/j.tate.2007.01.004

Vygotsky, L. (1978). Mind in society. Cambridge, MA: Harvard University Press.

Wang, C.-Y., Yang, H.-Y., \& Chou, S.-c. T. (2008). Using peer-to-peer technology for knowledge sharing in communities of practices. Decision Support Systems, 45(3), 528-540. doi: 10.1016/j.dss.2007.06.012

Wenger, E. (1998). Communities of practice: Learning, meaning and identity. New York: Cambridge University Press.

Wenger, E. (2009). Social learning capability: Four essays on innovation and learning in social systems. Unpublished manuscript.

Wenger, E., McDermott, R., \& Snyder, W. (2002). Cultivating communities of practice: A guide to managing knowledge. Boston: Harvard Business School Press.

Wenger, E., Tayner, B., \& de Laat, M. (2011). Promoting and assessing value creation in communities and networks: A conceptual framework. Amsterdam: Ruud de Moor Centrum. 
Wenger, E., White, N., \& Smith, J. (2009). Digital habitats: Stewarding technology for communities. Portland, OR: CPsquare.

Yin, R. K. (2009). Case study research: Design and methods (4th ed.). Thousand Oaks, CA: Sage.

Young, M. L., \& Tseng, F. C. (2008). Interplay between physical and online settings for online interpersonal trust formation in knowledge-sharing practice. Cyber Psychology \& Behavior, 11(1), 55-64. doi: 10.1089/cpb.2007.0019

Direct reprint requests to:

Dr. Sharon E. Booth

Friday Institute for Educational Innovation

1890 Main Campus Drive

Raleigh, NC 27606

e-mail: sherry_booth@ncsu.edu 